\title{
Effects of Small-Scale Armoring and Residential Development on the Salt Marsh-Upland Ecotone
}

\author{
Alyssa-Lois M. Gehman ${ }^{1}$ - Natalie A. McLenaghan ${ }^{2} \cdot$ James E. Byers $^{1}$ • \\ Clark R. Alexander ${ }^{2,3} \cdot$ Steven C. Pennings $^{4} \cdot$ Merryl Alber $^{2}$
}

Received: 12 October 2016 /Revised: 24 July 2017 / Accepted: 25 July 2017 /Published online: 29 August 2017

(C) The Author(s) 2017, corrected publication 2019

\begin{abstract}
Small-scale armoring placed near the marsh-upland interface to protect single-family homes is widespread but understudied. Using a nested, spatially blocked sampling design on the coast of Georgia, USA, we compared the biota and environmental characteristics of 60 marshes adjacent to either a bulkhead, a residential backyard with no armoring, or an intact forest. We found that marshes adjacent to bulkheads were at lower tidal elevations and had features typical of lower elevation marsh habitats: high coverage of the marsh grass Spartina alterniflora, high density of crab burrows, and muddy sediments. Marshes adjacent to unarmored residential sites had higher soil water content and lower porewater salinities than the armored or forested sites, suggesting that there may be increased freshwater input to the marsh at these sites. Deposition of Spartina wrack on the marsh-upland ecotone was negatively related to elevation at armored sites and positively related at unarmored residential and forested sites. Armored and unarmored residential sites had reduced
\end{abstract}

Communicated by Carolyn A. Currin

Electronic supplementary material The online version of this article (doi:10.1007/s12237-017-0300-8) contains supplementary material, which is available to authorized users.

Alyssa-Lois M. Gehman alyssamina@gmail.com

1 Odum School of Ecology, University of Georgia, 140 E. Green St, Athens, GA 30602, USA

2 University of Georgia, Marine Sciences, Marine Sciences Building, Athens, GA 30602, USA

3 Skidaway Institute of Oceanography, University of Georgia, 10 Ocean Science Circle, Savannah, GA 31411, USA

4 Biology and Biochemistry, University of Houston, 3455 Cullen Blvd, Houston, TX 77204, USA densities of the high marsh crab Armases cinereum, a species that moves readily across the ecotone at forested sites, using both upland and high marsh habitats. Distance from the upland to the nearest creek was longest at forested sites. The effects observed here were subtle, perhaps because of the small-scale, scattered nature of development. Continued installation of bulkheads in the southeast could lead to greater impacts such as those reported in more densely armored areas like the northeastern USA. Moreover, bulkheads provide a barrier to inland marsh migration in the face of sea level rise. Retaining some forest vegetation at the marsh-upland interface and discouraging armoring except in cases of demonstrated need could minimize these impacts.

Keywords Bulkheads - Residential development . Environmental impact $\cdot$ Spartina alterniflora $\cdot$ Armases cinereum · Shoreline armoring $\cdot$ Georgia Coastal Ecosystem LTER

\section{Introduction}

Humans have been living near, and protecting themselves from, the ocean for millennia (Doody 2004; Popkin 2015). Although it was historically assumed that coastal areas would accrete land on the seaward side of shoreline armoring or seawalls, creating more upland (Doody 2004), the modern understanding of the land-sea border suggests the opposite. Instead, hard structures steepen and shorten intertidal habitats, leading to a loss of area in a phenomenon known as coastal squeeze (Pethick 2001; Dugan et al. 2011). At present, $14 \%$ of the tidal shoreline within the continental US is armored, and armoring is expected to increase in the next century (Gittman et al. 2015). 
Armoring can be less effective at protecting the shoreline from erosion than natural defenses. For example, marshes provide greater erosion protection against the effects of a Category 1 storm than bulkheads (Gittman et al. 2014). In addition, the decrease in structural complexity associated with armoring often supports fewer species than found in natural shorelines (Chapman 2003; Gittman et al. 2015), and the introduction of novel substrate can facilitate species invasions (Landschoff et al. 2013). Many studies of coastal development and armoring have focused on the effects of extreme examples: development near dense human populations, or large seawalls in high-energy environments (Silliman and Bertness 2004; Long et al. 2011). Previous work also often examined armoring placed at low tidal elevation, or associated with new upland created by filling large areas (Long et al. 2011; Balouskus and Targett 2012; Lowe and Peterson 2014; Lowe and Peterson 2015). While these are important studies, they confound the effects of the armoring per se with the effects of intertidal habitat loss (but see Bozek and Burdick 2005).

Few studies have examined how the more commonplace, low-density residential development and more modest types of shoreline armoring affect coastal marsh habitats (Walters et al. 2010; Bozek and Burdick 2005). Small-scale forms of armoring, such as bulkheads, are commonly used to protect single-family homes that are adjacent to salt marshes in the southeastern US. Historically, these structures were installed to fill and reclaim land (Doody 2004). Although rules vary from state to state, filling of marshes is now generally prohibited. However, homeowners still often place bulkheads at the marsh-upland ecotone in order to guard against erosion, sea level rise, and flooding (Scyphers et al. 2014). These types of structures are typically about $1 \mathrm{~m}$ tall and located at or just above the high-tide line. The few studies of modest armoring in low-density residential developments have typically found few or very subtle effects rather than large effects, with effects concentrated in the high marsh (Bozek and Burdick 2005; Walters et al. 2010). These studies, however, may have suffered from limited replication (four to five pairs of developed and control sites) and only considered one type of development.

In this study, we aimed to evaluate the effect of placing a hard substrate at the upland-marsh ecotone by studying bulkheads that were placed above the high-tide mark adjacent to salt marshes. It is likely that these bulkheads have less of an effect than those placed lower in the tidal profile or in higher energy environments (Dugan et al. 2017). However, we hypothesize that they still alter the flow of fresh water and associated nutrients from the upland to the marsh, and impede the movement of animals in both directions. Severing sediment supply from the upland may result in lower elevations next to bulkheads, which could alter plant and invertebrate communities. For example, armoring can sequester sediments previously supplied by an eroding upland, leading to sediment starvation of environments seaward of the structure (Nordstrom et al. 2009; Nordstrom and Jackson 2013). It is possible, however, that not all the effects of armoring are negative: armoring may protect the upper marsh by limiting runoff from upland development.

Even if homeowners do not install bulkheads, residential development alone may have impacts on adjacent marsh ecosystems (McClelland et al. 1997; Bertness et al. 2002; Fitch et al. 2009). In the northeastern US, upland development has been linked to eutrophication and changes in the plant communities in the upper marsh (Bertness et al. 2002; Bozek and Burdick 2005; Fitch et al. 2009). However, development intensity is substantially lower in the southeast and the marshes are larger, so it is unclear whether results from the northeast can be extrapolated to the US east coast as a whole. The small amount of work that has been conducted in the southeastern US suggests that, in fact, these marshes show subtler and different responses to development than do those in New England (Walters et al. 2010). The southeastern US coast is projected to have the highest rate of human population growth from 2010 to 2020 in the coastal US (Crossett et al. 2005; Bamford 2013), so it is important both to understand impacts of current coastal development and predict the effects of more intense, future development in this area.

To separate the effects of low-intensity residential development and shoreline armoring, we compared salt marshes adjacent to upland that was (1) armored and developed ("armored" sites); (2) unarmored and developed ("unarmored" sites); and (3) unarmored and forested ("forested" sites). We hypothesized that upland modifications at either type of developed site would alter the extent and composition of the high marsh community, with marshes adjacent to bulkheads exhibiting the greatest effects because the upland was both developed and armored. Focusing on the upper salt marsh, we evaluated how site type affected the following: (1) physical and environmental characteristics; (2) biological characteristics; (3) the relationship between physical and biological characteristics; and (4) the use of terrestrial habitats by an organism that moves routinely between the upland and marsh.

\section{Methods}

\section{Field Survey Design and Site Selection Methods}

We surveyed high marsh characteristics at 20 blocked stations (Fig. 1) along the Georgia coastline. We used GIS data on the locations of armored shorelines (Alexander 2010) and land use to select an armored, unarmored, and forested site at each station ( 20 stations $\times 3$ site types $=60$ sampling sites $)$. We limited our armored sites to locations where the bulkhead was placed at the marsh-upland boundary, adjacent to a single-family home. None of the armored sites displayed obvious evidence of buildout (i.e., armoring that directly covers and replaces marsh) based on an evaluation of current and historical (1942, 1972, and 2009/2010) aerial photography. Bulkheads were between 


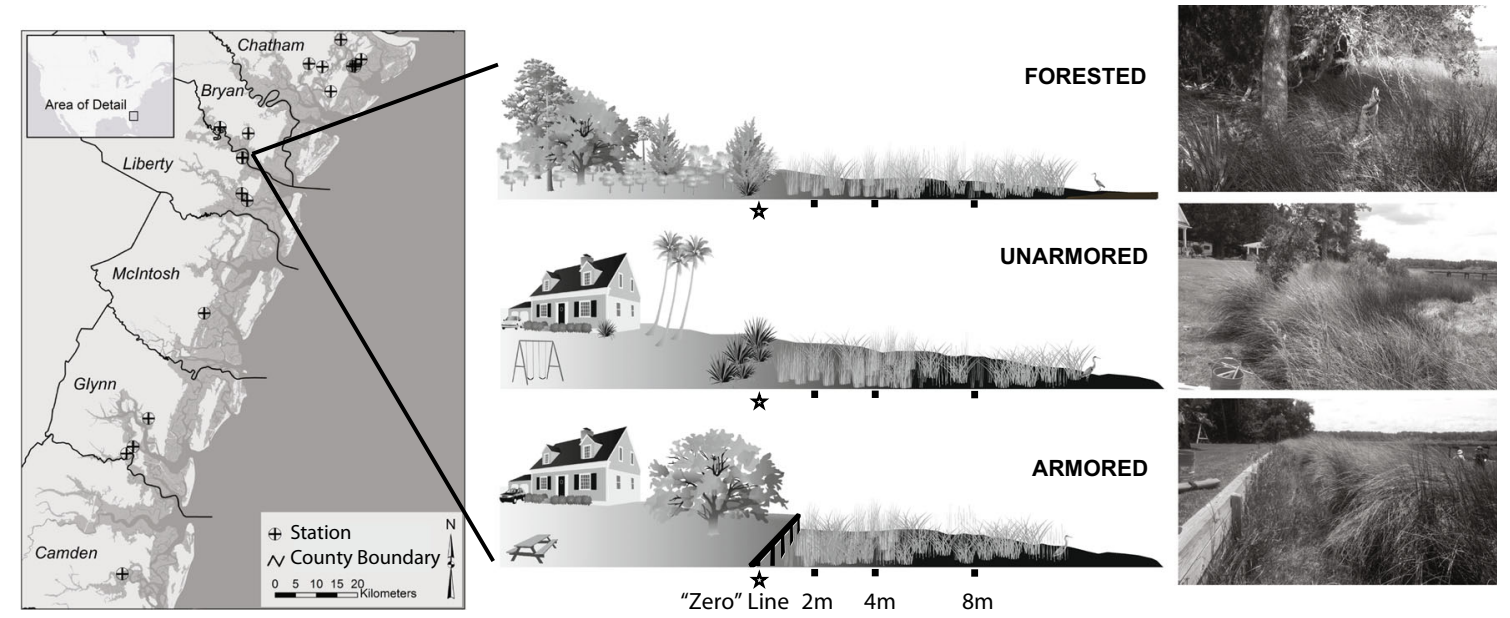

Fig. 1 Location of high marsh survey stations in coastal Georgia (map, left). At each station we selected three sites varying in site type categorization (forested, unarmored, armored), with sampling points at three distances (black bars, 2, 4, and $8 \mathrm{~m}$ ) from the marsh-upland boundary (starred), along two transects (one transect shown in illustration; middle panel). Illustrations at the right provide an example of each site type from within a single station of the survey

Porewater was collected from surficial soils at each sampling point using Rhizon Core Solution Samplers with a 10$\mathrm{cm}$ hydrophilic porous polymer tube (Rhizosphere Research Products). Samples were frozen at $-80^{\circ} \mathrm{C}$ prior to conducting analyses for porewater nutrient content and salinity. Ammonium concentrations were determined using the phenol-hypochlorite method (Koroleff 1983) with a Shimadzu UV-1601 spectrophotometer. Nitrate + nitrite (reported as nitrate) and phosphate concentrations were measured on an Alpkem RFA-300 autoanalyzer. We used EPAapproved methods to analyze nitrate $\left(4500-\mathrm{NO}_{3}{ }^{-}\right.$automated cadmium reduction method) and phosphate (4500-P automated ascorbic acid reduction method) (Rice et al. 2012). All nutrient samples were analyzed in triplicate. We measured salinity in collected porewater with a handheld refractometer (Vee Gee STX-3).

To evaluate sediment organic matter and water content, we collected a $10-\mathrm{cm}$ sediment core from each sampling point. Samples were stored at ambient temperature and brought to the lab for processing. Sediment water content was measured by drying samples for 3 days at $60{ }^{\circ} \mathrm{C}$. Sediment organic content was determined by weight loss after combustion at $440{ }^{\circ} \mathrm{C}$ overnight. We collected sediment samples from the marsh surface $(0-2 \mathrm{~cm})$ in each quadrat for grain size analysis. Sediment samples were wet-sieved using standard protocols through a 63- $\mu \mathrm{m}$ (4-phi) sieve (Alexander et al. 1986). The coarse fraction $(>63 \mu \mathrm{m})$ was then dried and sieved through stacked sieves starting at -1 phi $(2 \mathrm{~mm})$ to separate gravel (larger than $2 \mathrm{~mm})$ from sand $(2 \mathrm{~mm}-63 \mu \mathrm{m})$ at 0.25 -phi intervals. The percentage of mud $(<63 \mu \mathrm{m})$ was quantified by drying an aliquot of the total mud fraction captured during wet sieving. If sufficient quantities of mud existed ( $>10 \%$ by weight), the silt and clay grain size distributions were determined with a Micromeritics Sedigraph 5100. If the sample 
contained $<10 \%$ mud, an additional aliquot was taken to quantify the percent silt and clay in the sample. Sediment statistics (e.g., mean size and sorting; standard deviation) were derived from these data using the method of moments (Griffiths 1967). At each sampling site, we collected a 30$\mathrm{cm}$ core $2 \mathrm{~m}$ from the marsh-upland boundary for stratigraphic analysis; we described cores using the grain size nomenclature of Folk (1980) to illustrate broad-scale, down-core trends in sediment character.

Statistical Analysis All statistical analyses were done using R 3.1.3 (R Development Core Team 2015). To evaluate the relationship of site type with physical and environmental characteristics, we fit linear mixed-effects models. First we evaluated the relationship between site type, elevation, and upland-creek distance with linear mixed-effects models, using site type as the fixed effect and station and sampling point along the transect nested in station as the random effect (packages lme4 and ImerTest; Bates et al. 2014; Kuznetsova et al. 2015). Because elevation and upland-creek distance are known to affect many other environmental variables in a salt marsh (Hladik and Alber 2014), we analyzed each environmental response with the linear mixed-effects model just described, but with the addition of elevation and upland-creek distance as fixed effects. All models were run initially with an interaction between elevation and site type, which was retained if the interaction term was significant or if including it qualitatively changed model results. To compare all site types, we conducted Tukey's post hoc analysis (package multcomp; Hothorn et al. 2008). Data were evaluated for model assumptions and some variables were log or logit transformed to satisfy assumptions.

\section{Question 2: How does site type affect the biological community of the upper marsh?}

We quantified flora (vegetation composition) and fauna (snail, bivalve, and crab abundance) in the upper marsh ecotone. We measured vegetative cover in two ways; first we took an overhead photograph of every sampling point to produce an estimate of total vegetative cover. Next, we measured percent cover of each plant species at each sampling point using a $0.5 \times 0.5 \mathrm{~m}$ quadrat subdivided into 100 cells. Wrack and bare mud (no vegetation or wrack) were included as categories. We counted eastern melampus snails (Melampus bidentatus), and marsh periwinkles (Littoraria irrorata; Melampus and Littoraria, respectively, henceforth), and any other snails visible in a $0.25 \times 0.25 \mathrm{~m}$ quadrat in each sampling point. If snails were rare, we used a larger quadrat size, up to $1 \times 1 \mathrm{~m}$. Crabs are highly mobile and affected by human presence, so we counted crab burrows ( $>0.5 \mathrm{~cm}$ diameter) in a $0.25 \times 0.25 \mathrm{~m}$ quadrat as a proxy for their density (Mouton and Felder 1995). We identified as many crabs as possible upon arriving at each sampling point. We counted the ribbed mussel Geukensia demisa in a $1 \times 1 \mathrm{~m}$ quadrat.
Bulkheads can provide novel hard substrate, which can lead to new (and sometimes invasive) species recruiting to areas with armoring. At the bulkhead sites, we counted species living on the bulkhead by searching a 5-m length (usually between the two transects), and identifying benthic invertebrates such as barnacles, mobile crustaceans such as crabs, macroalgae, and any other species using the bulkheads as habitat.

Statistical Analysis To compare the biological communities among site types, we fit Bray-Curtis similarity matrices for abundance and percent cover data for all quadrats and visualized these matrices with Multidimensional Scaling (MDS). The advantage of MDS analysis is that it collapses the complex variability of species composition and abundance to major modes of variability among site types (Clarke and Warwick 2006; Siddon et al. 2011). To lower the influence of highly abundant species on the analyses, data were squareroot transformed prior to analysis. We applied multivariate ANOVA using the Bray-Curtis similarity matrices (package adonis) to test for the effect of site type on marsh biological communities, with site type as well as sampling point along the transect nested in station ( $\mathrm{R}$, package vegan; Oksanen et al. n.d.). We conducted a similarity of percentages (SIMPER) analysis to evaluate the contribution of each species to the Bray-Curtis similarity matrices to determine which species contributed most to differences among biological communities by site type.

\section{Question 3: How does site type affect the relationship between the physical and biological characteristics in the upper marsh?}

Statistical Analysis To evaluate the relationship between the environmental variables and biological community composition, we performed additional statistical analyses informed by the output from Question 2. MDS collapses the variance in the biological community to three axes, so we used a multivariate ANOVA (package car; Fox and Weisberg 2011) with the three axes of the MDS output as the response variables. Elevation, percent sand, soil water content, soil organic matter, porewater salinity, and porewater concentrations of ammonium, nitrate, and phosphate were used as environmental predictor variables.

To further evaluate the response of individual species, we used the outputs from the MDS and the multivariate ANOVA as a guide and correlated the distribution of the top species that contributed to the differences between site types and the top environmental variables that were associated with the biological community. We fit mixed-effects linear or generalized linear models to the top four species (or organism proxy in the case of crabs burrows) contributing to differences in the biological community based on output from the SIMPER analysis in Question 2. These were percent cover of Spartina alterniflora and Juncus romerianus (hereafter Spartina and Juncus, respectively), crab 
burrow counts, and Littoraria abundance. Because we used a gridded quadrat method, our percent cover data derives from cumulative presence/absence data, and so we used a linear model and logit transformed Spartina and Juncus percent cover. We used a Poisson model for the crab burrow counts and a linear model for log-transformed Littoraria abundance. We used environmental variables that were correlated with the biological community as predictor variables. Our study was conducted along the entire Georgia coast, and many of the variables included in our survey likely vary across this biogeographic range. To account for our sampling design and tease apart the relationships between the environmental variables and biological variables across the geographic range, we used station and sampling point along the transect $(2,4$, or $8 \mathrm{~m})$ as a random effect in each individual model (packages lme4 and lmerTest; Bates et al. 2014; Kuznetsova et al. 2015). To compare all site types, we conducted Tukey's post hoc analysis (package multcomp; Hothorn et al. 2008).

\section{Question 4: Does site type affect the movement of organisms between the marsh and the upland?}

To estimate the effect of a physical barrier on the use of upland habitats by marsh species, we documented use of the upland by the squareback crab Armases cinereum (Armases, henceforth). Because human presence changes crab behavior, one member of the research team walked the upland-marsh border immediately upon arrival at the site. Armases crabs were counted in $1 \times 4 \mathrm{~m}$ quadrats in the upper marsh and in the upland ( $-0.5 \mathrm{~m}$ and $+0.5 \mathrm{~m}$ from the "zero" line or bulkhead; $n=3$ per site). To verify the robustness of the quadrat counts, we employed a pitfall trap survey (Supporting Information).

Statistical Analysis We used a generalized linear mixedeffects model to examine the number of Armases counted in the upland (Poisson distributed), with the number of Armases in the marsh as a covariate and station included as a random variable to account for geographic variation in the data (package lme4; Bates et al. 2014).

\section{Results}

\section{Field Survey}

Spartina alterniflora (Spartina) and J. romerianus (Juncus) dominated the plant community at our sampling sites. However, Spartina cynosuroides, Spartina bakeri, Salicornia depressa, Borrichia frutescens, Iva frutescens, and Schoenoplectus sp. were all observed in at least one plot. The dominant invertebrates in marsh plots were L. irrorata (Littoraria) and crabs. Crab species associated with crab burrows included Armases cinereum, Uca pugnax, Uca minax, Uca pugilator, Sesarma reticulatum, and Eurytium limosum. There was no evidence of sessile marine invertebrates fouling any of the bulkheads. Armases were found on bulkheads at 11 locations, Littoraria were found on five bulkheads, and Uca pugnax were found on two bulkheads. In addition, we found Anolis carolinensis lizards on one bulkhead, Eumeces faciatus or Eumeces inexpectatus (five-lined skink or southeastern five-lined skink) on three bulkheads, and an unidentified snake on one bulkhead.

Elevations at all study sites were above $0 \mathrm{~m}$, and the extent of the marsh from the upland-creek distance ranged from 13 to $487 \mathrm{~m}$ (Table 1). Armored sites had the minimum elevation, upland-creek distance, soil water content (a proportion of 0.22$)$, phosphate concentration $(0 \mu \mathrm{M})$ and crab burrow density $\left(0 \mathrm{~m}^{-2}\right)$, the maximum salinity (52), and percent sand (92\%), and the minimum and maximum proportion of soil organic matter $(0.02$ and 0.80$)$ and crab burrow density ( 0 and $560 \mathrm{~m}^{-2}$; Table 1$)$. Unarmored sites had the minimum salinity (2.0), proportion of soil organic matter $(0.02)$, ammonium $(0.5 \mu \mathrm{M})$ and phosphate concentrations $(0 \mu \mathrm{M})$, and the maximum elevation $(1.5 \mathrm{~m})$ and soil water content $(0.81$; Table 1$)$. Forested sites had the minimum percent sand $(4.0 \%)$ and the maximum uplandcreek distance $(487 \mathrm{~m})$, Littoraria density $\left(720 \mathrm{~m}^{-2}\right)$, and ammonium $(157 \mu \mathrm{M})$, nitrate $(378 \mu \mathrm{M})$, and phosphate $(65 \mu \mathrm{M})$ concentrations (Table 1). Other parameters (Spartina and Juncus cover, nitrate concentration, fraction of bare surface and wrack cover) maximum and minimum overlapped among site types (Table 1). All data from this survey are available at (Gehman 2016).

\section{Question 1: How does site type affect the physical and environmental characteristics of the upper marsh?}

Site types varied in terms of elevation and upland-creek distance, both of which were correlated with other environmental variables. Elevation was significantly lower at armored than unarmored or forested sites (Table 2, Fig. 2). Higher elevations were associated with lower salinity, soil organic matter, ammonium and phosphate concentration, and higher percent sand, soil water content, and nitrate concentration (Table 2; Figs. 3 and 4). Upland-creek distance was longer at forested than at armored or unarmored sites (Table 2; Fig. 2). Longer upland-creek distance was associated with higher ammonium and phosphate concentrations, more bare (unvegetated) space, and lower salinity (Table 2; Figs. 3 and 4).

After accounting for the effects of elevation and uplandcreek distance, several significant effects of site type remained. First, salinity was lower at the unarmored sites than at the forested sites (Table 2, Fig. 3A). Second, soil water content was higher at unarmored sites than at armored and 
Table 1 The mean, minimum, and maximum values from the survey for each of the variables by site type. It should be noted that the mean presented here may be misleading and may conflict with the statistical results, as it is the simple arithmetic mean calculated without regard to geographic location (station) or sampling point along the transect (i.e., 2, 4 , or $8 \mathrm{~m}$ from the upland). For summarized data accounting for sampling point along the transect, see Table S5.1

\begin{tabular}{|c|c|c|c|c|c|c|c|c|c|c|}
\hline \multirow[t]{2}{*}{ Variable } & \multicolumn{3}{|c|}{ Armored } & \multicolumn{3}{|c|}{ Forested } & \multicolumn{3}{|c|}{ Unarmored } & \multirow[t]{2}{*}{ Unit } \\
\hline & Mean & Min & $\operatorname{Max}$ & Mean & Min & $\operatorname{Max}$ & Mean & Min & $\operatorname{Max}$ & \\
\hline Elevation & 0.87 & 0.27 & 1.2 & 0.96 & 0.32 & 1.4 & 0.94 & 0.50 & 1.4 & $\mathrm{~m}$ \\
\hline Upland-creek & 95 & 13 & 314 & 209 & 24 & 487 & 114 & 13 & 358 & $\mathrm{~m}$ \\
\hline Porewater salinity & 24 & 2.5 & 52 & 24 & 8.5 & 35 & 22 & 2.0 & 39 & \\
\hline Soil water content & 0.48 & 0.22 & 0.75 & 0.44 & 0.25 & 0.70 & 0.51 & 0.25 & 0.81 & Proportion \\
\hline Sand & 56 & 5.1 & 97 & 70 & 4.0 & 95 & 61 & 5.9 & 96 & $\%$ \\
\hline Soil organic matter & 0.21 & 0.02 & 0.80 & 0.19 & 0.03 & 0.73 & 0.25 & 0.02 & 0.77 & Proportion \\
\hline Ammonium & 19 & 0.60 & 129 & 30 & 0.80 & 157 & 20 & 0.50 & 120 & $\mu \mathrm{M}$ \\
\hline Nitrate & 1.9 & 0 & 53 & 8.6 & 0.00 & 378 & 9.6 & 0.00 & 336 & $\mu \mathrm{M}$ \\
\hline Phosphate & 8.5 & 0 & 58 & 8.6 & 0.20 & 65 & 7.6 & 0.00 & 58 & $\mu \mathrm{M}$ \\
\hline Fraction bare & 0.62 & 0.10 & 0.99 & 0.73 & 0.03 & 1.0 & 0.72 & 0.03 & 1.0 & Proportion \\
\hline Wrack & 25 & 0 & 100 & 31 & 0.00 & 100 & 34 & 0.00 & 100 & $\%$ \\
\hline Spartina & 61 & 0 & 100 & 44 & 0.00 & 100 & 43 & 0.00 & 100 & $\%$ \\
\hline Juncus & 23 & 0 & 100 & 30 & 0.00 & 100 & 24 & 0.00 & 100 & $\%$ \\
\hline Crab burrows & 139 & 0 & 560 & 99 & 8.0 & 232 & 97 & 8.0 & 400 & burrows $\mathrm{m}^{-1}$ \\
\hline Littoraria & 46 & 0 & 432 & 80 & 0.00 & 720 & 34 & 0.00 & 176 & snails $\mathrm{m}^{-2}$ \\
\hline
\end{tabular}

forested sites (Table 2, Fig. 3C, d). Third, the fraction bare of vegetation was higher at unarmored sites than at armored sites (Table 2, Fig. 4I, J). In one case, the interaction of Spartina wrack cover and elevation was significant (Table 2); wrack cover at armored sites was greater at lower elevations, whereas at unarmored sites it was greater at high elevations (Table 2, Fig. 4K).

Table 2 Results of mixed-effects models that evaluated the effects of elevation, upland-creek distance, and site type (armored (A), unarmored $(\mathrm{U})$, and forested (F)) on a suite of environmental variables in the upper marsh ecosystem. Each environmental variable was analyzed in a separate mixed-effect model. $\beta$-coefficients are reported for elevation, upland-

\section{Question 2: How does site type affect the biological community of the upper marsh?}

Four members of the biological community accounted for $\sim 70 \%$ of the dissimilarity between marsh communities adjacent to the different site types: Spartina, Juncus, Littoraria, and crabs (as indexed by their burrows; Table 3). Although the

creek distance, and site comparisons; variance is reported for the random variable of station and sampling point along the transect $(2,4$, or $8 \mathrm{~m}$ from the upland) nested within station. Significant coefficients are indicated by * (i.e., $p<0.05$ ). In the case of wrack, model results for the site comparisons include the significant interaction of site type and elevation

\begin{tabular}{|c|c|c|c|c|c|c|c|c|c|c|c|}
\hline Variable & Elevation & $\begin{array}{l}\text { Upland- } \\
\text { creek }\end{array}$ & $\mathrm{U} / \mathrm{A}$ & $\mathrm{F} / \mathrm{A}$ & $\mathrm{U} / \mathrm{F}$ & $\begin{array}{l}\text { U/A by } \\
\text { elev }\end{array}$ & $\begin{array}{l}\text { F/A by } \\
\text { elev }\end{array}$ & $\begin{array}{l}\mathrm{U} / \mathrm{F} \text { by } \\
\text { elev }\end{array}$ & Station & $\begin{array}{l}\text { Station: sampling } \\
\text { point }\end{array}$ & Transformation \\
\hline Elevation & & -0.01 & $0.07 *$ & $0.11 *$ & -0.03 & & & & 0.01 & 0.02 & \\
\hline Upland-creek & -4.88 & & 20.53 & $116.27 *$ & $-95.74 *$ & & & & 5835 & 0 & \\
\hline Salinity & $-1.2 *$ & $-1.4^{*}$ & -1.38 & 1.62 & $-3.01^{*}$ & & & & 44.01 & 0 & \\
\hline $\begin{array}{r}\text { Soil Water } \\
\text { Content }\end{array}$ & $0.07 *$ & 0.00004 & $0.05^{*}$ & -0.005 & $0.05^{*}$ & & & & 0.005 & 0 & \\
\hline$\%$ Sand & $16.99 *$ & 0.49 & -0.66 & 6.51 & -7.17 & & & & 75.1 & 17.10 & \\
\hline Soil OM & $-0.35^{*}$ & 0.14 & 0.18 & -0.095 & 0.27 & & & & 0.20 & 0 & $\log$ \\
\hline $\mathrm{NH}_{4}$ & $-0.27^{*}$ & $0.32 *$ & -0.13 & 0.29 & -0.42 & & & & 0.21 & 0 & $\log +0.0001$ \\
\hline $\mathrm{NO}_{3}$ & $0.47^{*}$ & -0.020 & -0.014 & -0.13 & 0.12 & & & & 0.089 & 0.14 & $\log +0.0001$ \\
\hline $\mathrm{PO}_{4}$ & $-0.53^{*}$ & $0.65^{*}$ & 0.36 & 0.58 & -0.22 & & & & 0.85 & 0 & $\log +0.0001$ \\
\hline Fraction bare & -0.04 & $0.59 *$ & $0.42 *$ & 0.02 & 0.39 & & & & 0.53 & 0 & logit \\
\hline Wrack & -0.43 & 0.16 & 0.47 & 0.33 & -0.14 & $0.79 *$ & 0.45 & -0.34 & 2.27 & 0 & logit \\
\hline
\end{tabular}




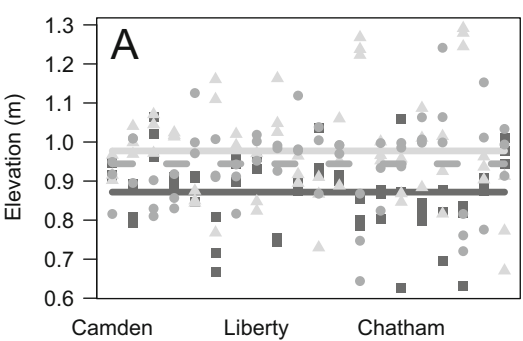

Fig. 2 Mixed model fit of $\mathbf{A}$ elevation and $\mathbf{B}$ upland-creek distance by site type. Points represent partial residuals of the data, and are shown by station in geographic order from south (Camden County) to north

biological communities were different by site type and sampling point along the transect, the multivariate ANOVA model explained little of the variability in the data (Table 4).

\section{Question 3: How does site type affect the relationship between the physical and biological characteristics in the upper marsh?}

Seven environmental variables were correlated with the structure of the biological community: elevation, uplandcreek distance, porewater salinity, soil water content, porewater concentrations of nitrate and phosphate, and wrack cover (multivariate ANOVA, Table 5).

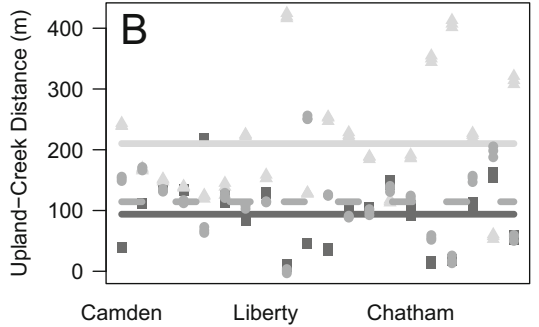

(Chatham County). Armored sites are denoted by black square symbols and solid lines, unarmored sites by gray circles and dashed lines, and forested sites by light gray triangles and solid lines

Spartina had greater coverage at armored versus unarmored sites (generalized mixed modeling, Table 6, Fig. 5). It also had greater coverage at sites with lower elevations, higher salinity and soil water content, and lower wrack cover and porewater phosphate concentrations (Table 6, Fig. 5). Spartina coverage was lower at stations with longer uplandcreek distances. Juncus coverage was not affected by site type, but there was greater coverage at sites with lower soil water content and wrack cover (Table 6, Fig. 5). There were more crab burrows at forested sites, followed by armored sites and then unarmored sites. More crab burrows were also found at stations with shorter upland-creek distance and sites with lower elevation, porewater phosphate, and wrack coverage, and
Fig. 3 Mixed-effects model fit of porewater salinity (Salinity, $\boldsymbol{A}, \boldsymbol{B})$, percent soil water content (Soil Water, $\boldsymbol{C}, \boldsymbol{D})$ and percent sand $(\%$ Sand, $\boldsymbol{E}, \boldsymbol{F})$ as a function of elevation (left column) and upland-creek distance (right column). Armored sites are denoted by black square symbols and solid lines, unarmored sites by gray circles and dashed lines, and forested sites by light gray triangles and solid lines. Points represent partial residuals
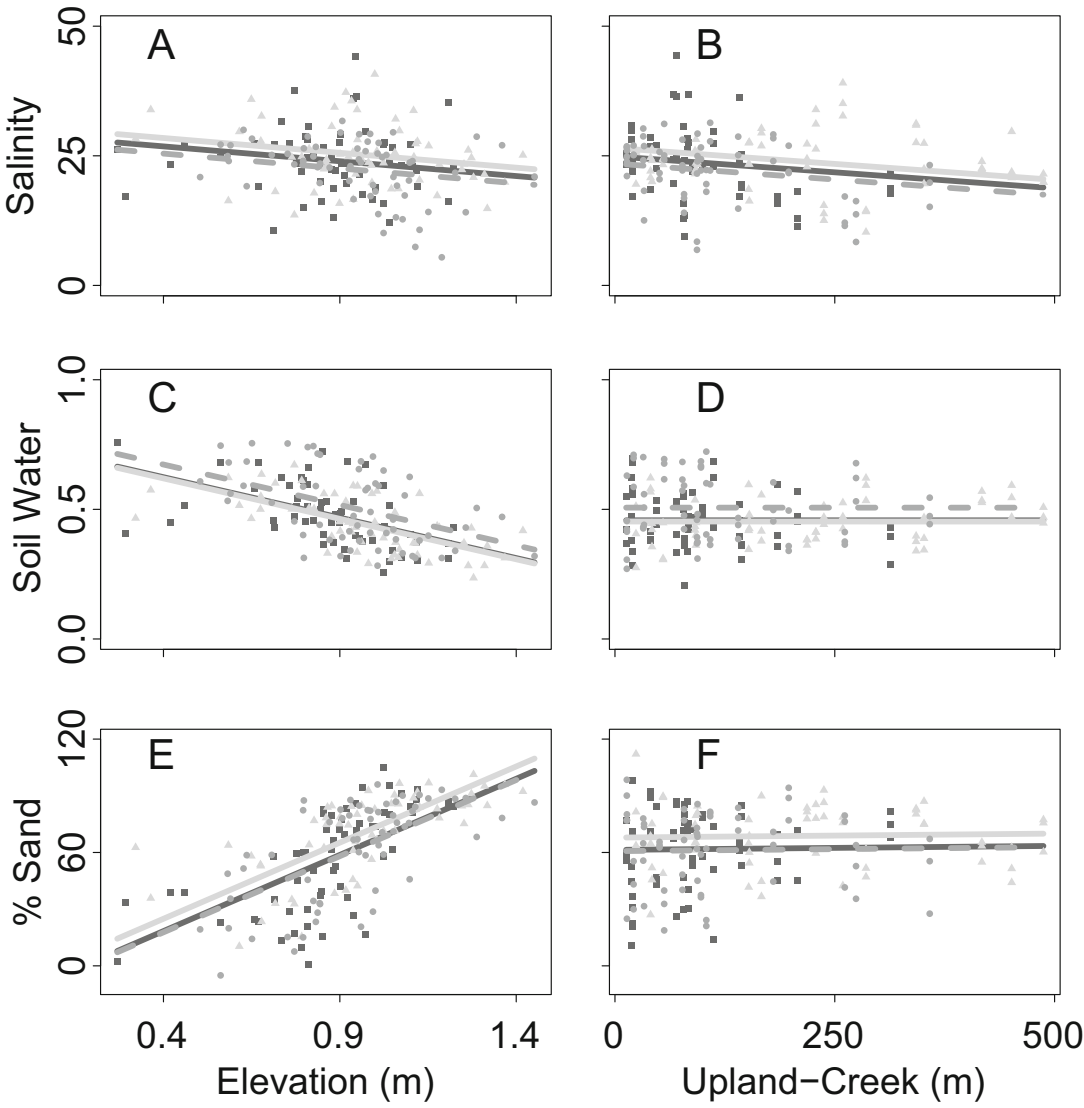

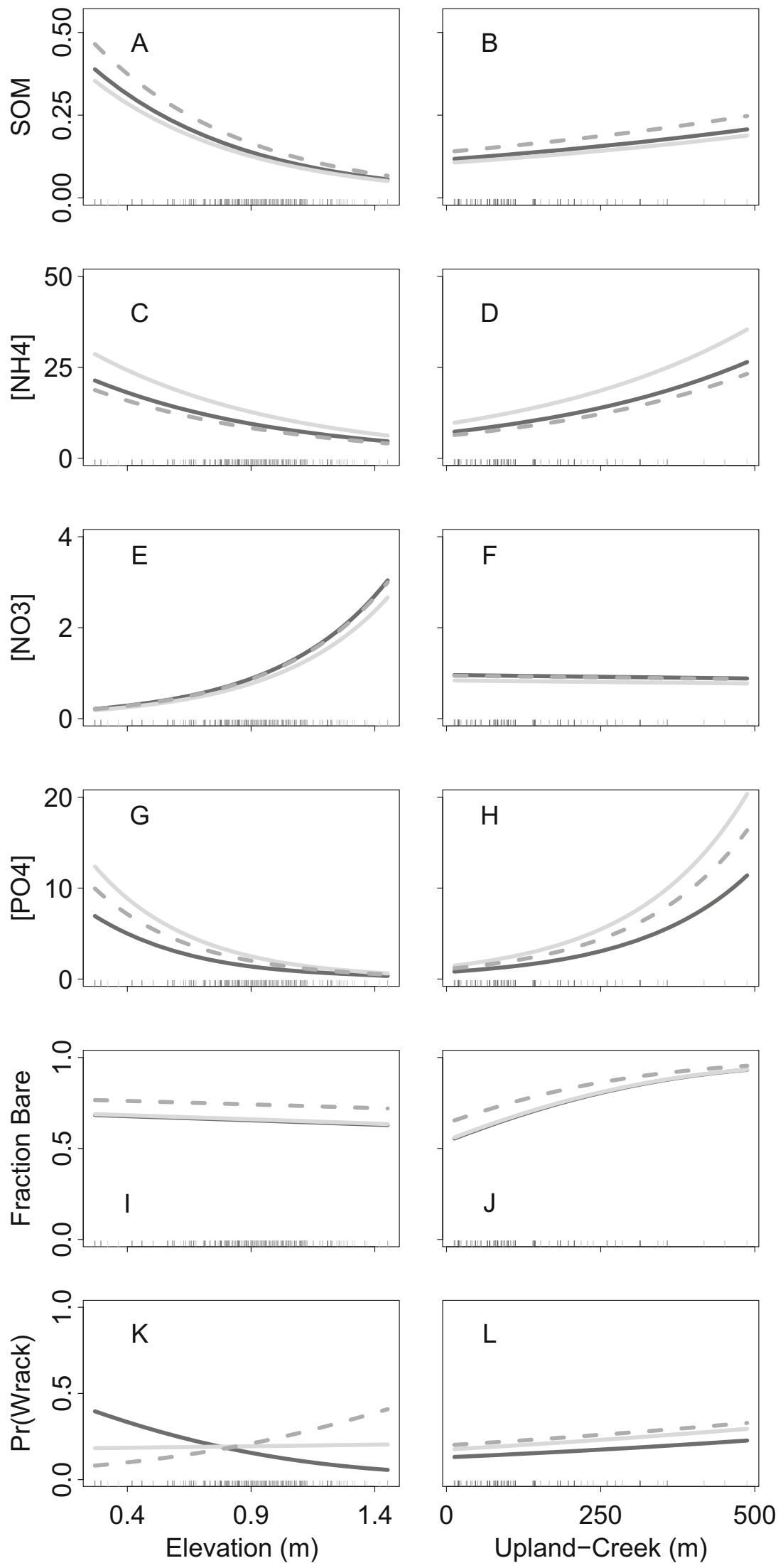
Fig. 4 Mixed-effects model fit of percent soil organic matter (SOM, $\boldsymbol{A}$, $\boldsymbol{B})$, porewater ammonium $(\mathrm{NH} 4)$, nitrate $(\mathrm{NO} 3)$ and phosphate $(\mathrm{PO} 4)$ concentrations in milligram/gram $(\boldsymbol{C}, \boldsymbol{H})$, the fraction of bare soil (Fraction Bare, $\boldsymbol{I}, \boldsymbol{J})$, and the probability of wrack cover (Pr(Wrack), $\boldsymbol{K}$, $\boldsymbol{L})$ as a function of elevation (left column) and upland-creek distance (right column). Armored sites are denoted by black solid lines, unarmored sites by gray dashed lines, and forested sites by light gray solid lines. In contrast to Fig. 3, partial residuals are not shown because these models are binomial fits and log-transformed response variables. Internal tic marks denote the distribution of observations with respect to elevation (left column) or distance (right column)

higher salinity, soil water content, and porewater nitrate concentrations (Table 6, Fig. 5). Littoraria densities were not affected by site type, but there were more Littoraria at sites with longer upland-creek distances and with lower nitrate concentration and wrack coverage (Table 6, Fig. 5).

\section{Question 4: How does site type affect the use of terrestrial habitats by organisms that routinely move between the upland and marsh?}

The number of Armases found in the upland varied by site type, with the highest densities at forested sites, then unarmored sites, and the lowest counts at armored sites (Table 7 , Fig. 6). Additionally, the number of Armases found in the marsh was positively correlated to the number found in the upland (Table 7, Fig. 6).

\section{Discussion}

We found that shoreline armoring and development affected the environmental and biological structure of the upper marsh, but the effects were subtle rather than dramatic. Marshes adjacent to bulkhead armoring had lower elevations than those adjacent to unarmored or forested sites (Fig. 2), and the biological and physical characteristics of these marshes were consistent with a lower elevation. In particular, armored sites had greater Spartina coverage and crab burrow abundance than unarmored sites (Fig. 5). In addition, silty clay-a soil characteristic of tidal creek sediments - was only found adjacent to armored sites (Supporting Information).

Table 3 The cumulative contributions of the top four biological variables, Spartina alterniflora and J. romerianus (\% cover), and crab burrows and L. irrorata (number $\mathrm{m}^{-2}$ ), that together account for over $70 \%$ of the dissimilarity between marshes adjacent to the site types (as quantified using a SIMPER analysis)

\begin{tabular}{lcclc}
\hline Pairwise comparison & Spartina & Juncus & Crab burrows & Littoraria \\
\hline Armored and forested & $19.2 \%$ & $17.4 \%$ & $18.4 \%$ & $22.8 \%$ \\
Armored and unarmored & $20.9 \%$ & $16.9 \%$ & $21.2 \%$ & $18.6 \%$ \\
Forested and unarmored & $21.9 \%$ & $17.7 \%$ & $20.2 \%$ & $14.7 \%$ \\
\hline
\end{tabular}

Table 4 Test of the effect of site type (armored (A), unarmored (U), and forested $(\mathrm{F}))$ and sampling point along the transect $(2,4$, or $8 \mathrm{~m}$ from the upland) on the salt marsh biological communities as measured by multivariate ANOVA (package adonis)

\begin{tabular}{lllllll}
\hline & Df & SS & MS & $F$ & $R^{2}$ & $p$ value \\
\hline Site type & 2 & 0.30 & 0.15 & 1.38 & 0.015 & 0.032 \\
Sampling point & 1 & 0.69 & 0.69 & 6.33 & 0.034 & 0.001 \\
Residuals & 176 & 19.06 & 19.06 & 0.95 & & \\
\hline
\end{tabular}

The lower elevation associated with armored sites may be the result of increased erosion at bulkheaded sites after installation. Bulkheads and riprap without adjacent marsh habitats have also been shown to have lower elevation (measured as water depth; Kornis et al. 2017). However, it is also possible that the lower elevation reflects that the bulkheads themselves were built directly in marshland. Although we do not have preconstruction elevations to directly address this, installing a bulkhead directly in the marsh is against permit regulations that have been in place since 1970. Moreover, many of the bulkheads in this study were paired with neighboring homes in the same subdivision, and there is no a priori reason to expect that the observed differences in elevation occurred before the bulkheads were in place. Regardless of the history, local supply of sand from the upland can be cut off by the presence of the bulkheads, which would affect the ability of the upper marsh to accrete vertically (Edwards and Frey 1977; Frey and Basan 1985). The abrupt jump in elevation from high marsh to upland created by the bulkhead could remove transitional habitat for plant communities. We did not sample plants directly at the marsh-upland boundary, but Bozek and Burdick (2005) found that plant species richness at the marsh-upland boundary in

Table 5 Relationship between salt marsh environmental variables and biological community structure (represented by MDS output), indicating which variables are significantly correlated with differences in the biological community as measured by multivariate ANOVA. Significant variables were included in the Question 3, Table 6 analysis and are indicated by *

\begin{tabular}{lll}
\hline Variable & $F$ & $p$ value \\
\hline Elevation* & 30.49 & $<0.001$ \\
Upland-creek distance* & 9.00 & $<0.001$ \\
Salinity* & 11.37 & $<0.001$ \\
Soil water content* & 8.90 & $<0.001$ \\
Sand & 1.88 & 0.13 \\
Soil OM & 0.58 & 0.62 \\
$\mathrm{NH}_{4}$ & 1.96 & 0.12 \\
$\mathrm{NO}_{3}{ }^{*}$ & 6.37 & $<0.001$ \\
$\mathrm{PO}_{4}{ }^{*}$ & 3.61 & 0.015 \\
$\mathrm{Wrack}^{*}$ & 12.68 & $<0.001$ \\
\hline
\end{tabular}


Table 6 The effects of site type (armored (A), unarmored (U), and forested (F)) and the top environmental variables correlated with change in the biological community structure (from Table 5) on the top four species driving the changes in the biological communities (from Table 3) as tested through mixedeffects modeling. Variance is reported for the random variable of station, sampling point along the transect $(2,4$, or $8 \mathrm{~m}$ from the upland) nested in station, and $\beta$ coefficients are reported for the fixed variables. Significant coefficients are indicated by $*$ (i.e., $p<0.05)$

\begin{tabular}{llllll}
\hline & Variable & Spartina & Juncus & Crab burrows & Littoraria \\
\hline \multirow{2}{*}{ Variance } & Station & 1.38 & 2.66 & 0.19 & 1.42 \\
& Station/sampling point & 0 & 0 & 0.12 & 0 \\
& Intercept & 0.21 & $-2.04^{*}$ & $4.62^{*}$ & $2.62^{*}$ \\
& Unarmored/armored & $-0.78^{*}$ & 0.33 & $-0.25^{*}$ & 0.10 \\
& Forested/armored & -0.09 & 0.44 & $0.09^{*}$ & 0.37 \\
& Unarmored/forested & -0.68 & -0.11 & $-0.35^{*}$ & -0.27 \\
& Elevation & $-0.76^{*}$ & 0.10 & $-0.21^{*}$ & -0.12 \\
& Upland-creek & $-0.76^{*}$ & 0.18 & $-0.20^{*}$ & $0.35^{*}$ \\
& Salinity & $0.62^{*}$ & -0.24 & $0.27^{*}$ & -0.059 \\
& Soil water content & $0.65^{*}$ & $-0.73^{*}$ & $0.19^{*}$ & 0.070 \\
& NO 3 & -0.26 & -0.10 & $0.030^{*}$ & $-0.24^{*}$ \\
& PO & $-0.41^{*}$ & -0.31 & $-0.12^{*}$ & -0.19 \\
& Wrack & $-0.42^{*}$ & $-0.76^{*}$ & $-0.031^{*}$ & $-0.25^{*}$ \\
& Marginal $R^{2}$ & 0.41 & 0.21 & 0.18 & 0.10 \\
& Conditional $R^{2}$ & 0.58 & 0.57 & 0.42 & 0.58 \\
\hline
\end{tabular}

New Hampshire was reduced by $50 \%$ in areas with rock bulkheads, and it is likely that a similar effect occurred at our sites.

The most dramatic difference we found among site types was the effect on Armases, which is the one species we measured that readily moves across the ecotone. Armases was most abundant in the upland associated with the forested sites, with intermediate densities in unarmored sites and the fewest in armored sites (Fig. 6 and Table 7). These results were supported by a pitfall trap study that showed that Armases moved further into the upland at forested sites than at the other site types (Supporting Information). Armases likely prefers heavily wooded areas because it experiences less desiccation in shaded, cooler habitats, which may explain the decrease in Armases found at the unarmored and armored sites. Although field observations suggested that Armases is not able to climb some bulkhead materials, such as vinyl siding, only 7 of our 20 bulkheads were constructed with vinyl siding and Armases were regularly found on and inside wooden bulkheads. There are several other species that move across the upland-high marsh ecotone, including butterflies, grasshoppers, birds, and raccoons; future studies should evaluate how these species are affected by upland development (with and without armoring).

Contrary to our hypothesis that forested, unarmored, and armored sites would present a response gradient, we found that unarmored development, i.e., without a protective bulkhead, often had different, opposing effects on the upper marsh community than armored development. For example, wrack deposition adjacent to armoring was low and increased at lower elevations farther from the bulkhead, whereas at unarmored sites wrack deposition was enhanced with increasing elevation (Table 2, Fig. 4K). Wrack acts as a disturbance in salt marshes, as it can smother the underlying vegetation if it is present for a long enough period of time (Bertness and Ellison 1987; Valiela and Rietsma 1995; Li and Pennings 2016; Li and Pennings 2017), and in fact higher wrack cover was associated with lower Spartina and Juncus coverage and a decreased density of crab burrows and Littoraria (Table 6, Fig. 5). However, it is also a subsidy in that it provides a source of food and shelter for invertebrates such as isopods and amphipods, which represent food for higher trophic levels (e.g., spiders; Zimmer et al. 2002; Buck et al. 2003). The decrease in wrack associated with bulkheads observed here is similar to patterns that have been found adjacent to armored structures on open-coast beaches, where armored beaches poorly retained wrack deposits, subsequently leading to lower bird populations (Dugan et al. 2008; Sobocinski et al. 2010).

Marshes adjacent to unarmored sites in this study were characterized by higher soil water content than either armored or forested sites and had lower salinity than forested sites (Table 2, Fig. 3A, C). Taken together, this suggests that overland and groundwater input of freshwater to the marsh could be increased by development in the absence of a bulkhead. Increased freshwater input has been associated with unarmored development in South Carolina as well as the

Fig. 5 Mixed-effects models of the top four biological variables determining variance between sites (determined by MDS) as a function of the correlated environmental variables (as determined by multivariate ANOVA). Each column represents a single response variable, with the units for the $y$-axis labeled above the column. Spartina alterniflora and $J$. romerianus percent cover are reported on probability scales (inverse logit transformed). Each graph illustrates the biological response variable as a function of the physical variable at the 10th (dotted line), 50th (dashed line), and 90th (solid line) quantile of the physical variable, for armored $(A)$, forested $(F)$, and unarmored $(U)$ site types 


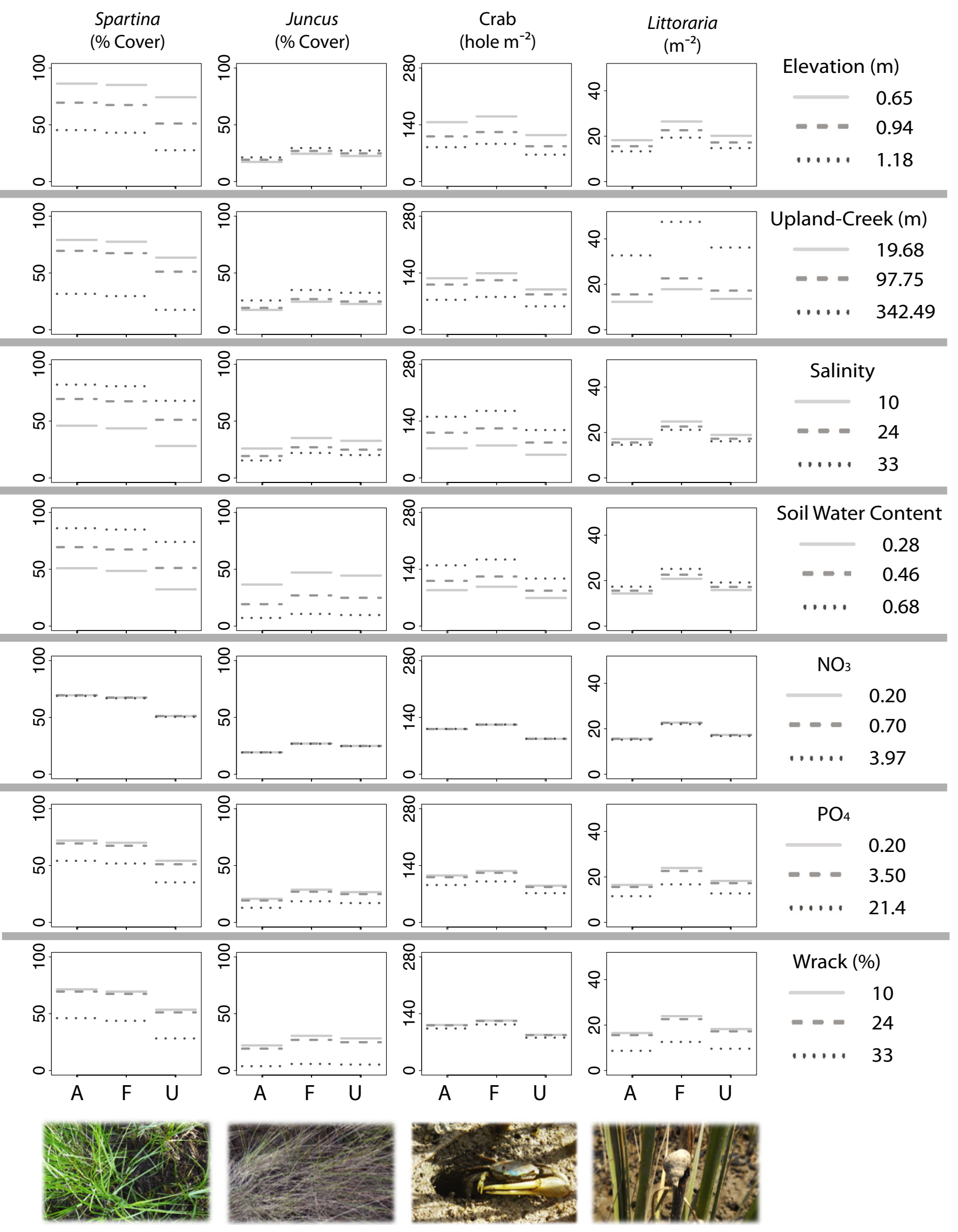


Table 7 Generalized linear mixed-effects model evaluating Armases movement into the upland as a function of the number found in the marsh, and site type $(\mathrm{A}=$ armored, $\mathrm{U}=$ Unarmored, $\mathrm{F}=$ forested $)$. Variance is reported for the random variable of Station, and $\beta$-coefficients are reported for the fixed variables. Significant coefficients are indicated by $*$ (i.e., $p<0.05)$

\begin{tabular}{lllllll}
\hline Variable & $\begin{array}{l}\text { Armases in } \\
\text { marsh }\end{array}$ & U/A & F/A & U/F & Station & Distribution \\
\hline Armases & $0.018^{*}$ & $1.44^{*}$ & $0.65^{*}$ & $-0.8^{*}$ & 1.88 & Poisson \\
\hline
\end{tabular}

northeastern US (Silliman and Bertness 2004; Walters et al. 2010). Armoring could ameliorate this effect by blocking water flow paths from the upland to the marsh or by decreasing runoff from the upland by reducing the land-surface gradient adjacent to the marsh. If so, it could be possible to alleviate the effect of unarmored development on the upper marsh by reducing freshwater input in other ways, for example through tying into a sanitary sewer system, collecting precipitation with rain barrels, and limiting the watering of lawns.

Forested sites were characterized by increased porewater salinity, higher density of crab burrows, and longer upland-creek distances compared to other site types (Tables 2 and 4, Figs. 2, 3, and 5). The longer upland-creek distances observed at forested sites may reflect a predilection for development to occur in areas with shorter distances to the water, making it easier to install docks. Although the blocked design of this study should have controlled for large-scale geographic variability in marshupland border characteristics, we could not control for preexisting differences among site types within a local area. This highlights the limitations of this type of field survey. If possible, we encourage coastal managers to require studies before development is initiated, enabling a before-after control-impact design that would better isolate the effects of development on marsh communities (Stewart-Oaten et al. 1986).

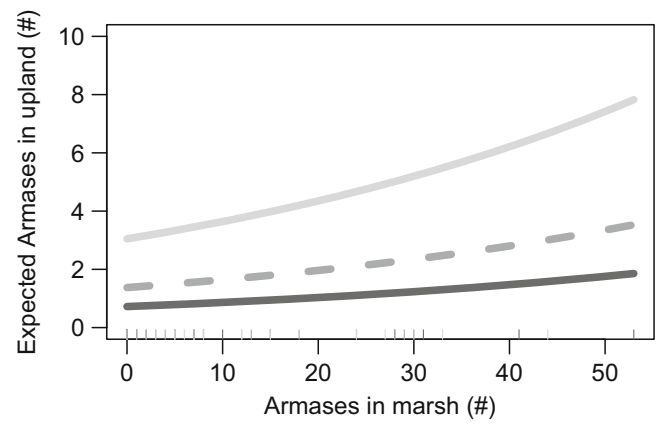

Fig. 6 Generalized linear mixed-effects model of the total number of Armases cinereum expected to be found in the upland as a function of the number of Armases found in the marsh and the site type, with station as a random variable. Armored sites are denoted by black solid line, unarmored sites by gray dashed line, and forested sites by light gray solid line
The effects of armoring and development on the upper marsh ecosystems in this study were characterized by subtler changes than those previously reported in the northeastern US or in open-coast systems (Wahl et al. 1997; Bertness et al. 2002; Dugan et al. 2011). There are several possible reasons for this difference. First, marsh ecosystems are relatively low energy compared to the open-coast systems where other armoring research has been conducted. Effects of shoreline armoring across soft-sediment environments appears to vary by energy and armoring type, and our work supports the hypothesis that the effects of armoring will be subtler in low energy systems (Dugan et al. 2017; Bozek and Burdick 2005). Second, the southeastern US coastline is relatively undeveloped (Crossett et al. 2005; Gittman et al. 2015). Thus, the southeast may not yet exhibit the cumulative effects of development that are present in highly developed coastal regions like New England (Walters et al. 2010). Third, we standardized the selection of bulkheads in our study, sampling only at structures that had not obviously reclaimed upland from the marsh. This excluded some of the structures with the greatest potential impacts, such as cases where the filled and armored area completely replaced the upper marsh, thereby removing this ecotone entirely. We eliminated these cases during site selection because such placement is no longer permitted in Georgia and because we were interested in studying the effects of bulkheads as barriers per se, without associated habitat destruction.

The coastal southeastern US is expected to see intense development in the future (Crossett et al. 2005). The impacts we measured could therefore become more widespread and increase in magnitude as more bulkheads are built. Our results suggest that the bulkheads block the supply of sand from upland areas, potentially resulting in vertical loss of elevation in the upper marsh (Edwards and Frey 1977). Moreover, the presence of a physical barrier limits the ability of marshes to migrate horizontally onto the upland, resulting in what is known as "coastal squeeze" (Doody 2004). In addition to limiting armoring, regulatory agencies can work to minimize the effects of residential development that we observed. For example, forest vegetation could be retained along the high marsh ecotone to provide a buffer that could serve to minimize freshwater runoff into the marsh and provide room for potential upward marsh migration. Forested vegetation could also potentially provide habitat for organisms such as Armases that routinely move between the marsh and the upland. Because the southeastern US presently has lower population densities and a limited extent of armoring in coastal marsh environments, proactive policy in this part of the country could help prevent the stronger effects of armoring and development that have been seen elsewhere. 
Acknowledgments We thank M. Mahaffey, K. Shaw, S. Shaw, G. Mills, K. McPherran, F. Li, C. Reddy, J. Shalack, and T. Montgomery for field assistance, and M. Robinson for RTK-GPS data processing. This work was a product of the Georgia Coastal Ecosystems LTER program, which is funded by NSF (OCE12-37140). This is contribution number 1052 from the University of Georgia Marine Institute.

Open Access This article is distributed under the terms of the Creative Commons Attribution 4.0 International License (http://creativecommons. org/licences/by/4.0/), which permits use, duplication, adaptation, distribution and reproduction in any medium or format, as long as you give appropriate credit to the original author(s) and the source, provide a link to Creative Commons license and indicate if changes were made.

\section{References}

Alexander, Clark R. 2010. GIS and field-based documentation of armored estuarine shorelines in Georgia. Final report to the Georgia Department of Natural Resources, Brunswick, GA. Brunswick: Final Report to the Georgia Department of Natural Resources.

Alexander, Clark R., Charles A. Nittrouer, and David J. DeMaster. 1986. High-resolution seismic stratigraphy and its sedimentological interpretation on the Amazon continental shelf. Continental Shelf Research 6: 337-357 Pergamon. doi:10.1016/0278-4343(86) 90067-1.

Balouskus, Richard G., and Timothy E. Targett. 2012. Egg deposition by Atlantic Silverside, Menidia menidia: substrate utilization and comparison of natural and altered shoreline type. Estuaries and Coasts 35: 1100-1109. doi:10.1007/s12237-012-9495-x.

Bamford, Holly. 2013. National coastal population report. National Oceanic and Atmospheric Administration, National Ocean Service, Management and Budget Office, Special Projects: 1-22.

Bates, Douglas, Martin Mächler, Ben Bolker, and Steve Walker. 2014. Fitting linear mixed-effects models using lme4. arXiv preprint arXiv.

Bertness, M.D., and A.M. Ellison. 1987. Determinants of pattern in a New England salt marsh plant community. Ecological Monographs 57: 129-147.

Bertness, Mark D., Patrick Ewanchuk, and Brian R. Silliman. 2002. Anthropogenic modification of New England salt marsh landscapes. Proceedings of the National Academy of Sciences 99: 1395-1398.

Bozek, Catherine M., and David M. Burdick. 2005. Impacts of seawalls on saltmarsh plant communities in the Great Bay estuary, New Hampshire USA. Wetlands Ecology and Management 13: 553568. doi:10.1007/s11273-004-5543-z.

Buck, T. L., G. A. Breed, S. C. Pennings, M. E. Chase, M. Zimmer, and T.H. Carefoot. 2003. Diet choice in an omnivorous salt-marsh crab: different food types, body size, and habitat complexity. Journal of Experimental Marine Biology and Ecology 292: 103-116.

Chapman, M.G. 2003. Paucity of mobile species on constructed seawalls: effects of urbanization on biodiversity. Marine Ecological Progress Series 264: 21-29.

Clarke, KR, and RM Warwick. 2006. Change in marine communities: an approach to statistical analysis and interpretation. 6th Edition. Plymouth: Primer-E Ltd.

Crossett, Kristen M, Thomas J Culliton, Peter C Wiley, and Timothy R Goodspeed. 2005. Population trends along the coastal United States: 1980-2008. National Oceanic and Atmospheric Administration, National Ocean Service, Management and Budget Office, Special Projects.: 1-54.
Doody, J. 2004. "Coastal squeeze" — an historical perspective. Journal of Coastal Conservation 10: 129-138.

Dugan, Jenifer E., David Hubbard, Iván F. Rodil, David Revell, and Stephen Schroeter. 2008. Ecological effects of coastal armoring on sandy beaches. Marine Ecology 29: 160-170.

Dugan, Jenifer E., L. Airoldi, M.G. Chapman, S.J. Walker, and T. Schlacher. 2011. Estuarine and coastal structures: environmental effects, a focus on shore and nearshore structures. Treatise on Estuarine and Coastal Science 8: 17-42. doi:10.1016/B978-0-12374711-2.00802-0.

Dugan, Jenifer E., K. A. Emery, M. Alber, C.R. Alexander, James E. Byers, A. L. M. Gehman, N. McLenaghan, and S. E. Sojka. 2017. Generalizing ecological effects of shoreline armoring across soft sediment environments. Estuaries and Coasts: 1-17. doi:10.1007/ s12237-017-0254-X.

Edwards, J.M., and R.W. Frey. 1977. Substrate characteristics within a Holocene salt marsh, Sapelo Island, Georgia. Senckenbergiana Maritima 9: 215-259.

Fitch, Rosemarie, Theresa Theodose, and Michele Dionne. 2009. Relationships among upland development, nitrogen, and plant community composition in a Maine salt marsh. Wetlands 29: 11791188.

Fox, John, and Sanford Weisberg. 2011. An $\{R\}$ companion to applied regression. second ed. Thousand Oaks: SAGE Publication.

Frey, R.W., and P.B. Basan. 1985. Coastal salt marshes. In Coastal sedimentary environments, ed. R.A. Davis Jr., 225-301. New York: Springer.

Gehman, A. 2016. Effects of small-scale armoring and residential development on the salt marsh/upland ecotone in coastal Georgia, USA. Georgia Coastal Ecosystems LTER Project, University of Georgia, Long Term Ecological Research Network. http://dx.doi.org/10. 6073/pasta/76497936543330a1895015df794ab077

Gittman, Rachel K., A.M. Popowich, and J.F. Bruno. 2014. Marshes with and without sills protect estuarine shorelines from erosion better than bulkheads during a Category 1 hurricane. Ocean \& Coastal Management 102: 94-102. doi:10.1016/j.ocecoaman.2014.09.016.

Gittman, Rachel K., F. Joel Fodrie, Alyssa M. Popowich, Danielle A. Keller, John F. Bruno, Carolyn A. Currin, Charles H. Peterson, and Michael F. Piehler. 2015. Engineering away our natural defenses: an analysis of shoreline hardening in the US. Frontiers in Ecology and the Environment 13: 301-307. doi:10.1890/150065.

Griffiths, J. 1967. Scientific method in analysis of sediments. New York: McGraw-Hill Book Company.

Hladik, Christine, and Merryl Alber. 2014. Classification of salt marsh vegetation using edaphic and remote sensing-derived variables. Estuarine, Coastal and Shelf Science 141: 47-57 Elsevier Ltd. doi:10.1016/j.ecss.2014.01.011.

Hothorn, Torsten, Frank Bretz, and Peter Westfall. 2008. Simultaneous inference in general parametric models. Biometrical Journal 50: 346-363.

Kornis, Matthew S, Donna M Bilkovic, Lori A Davias, Steve Giordano, and Denise L Breitburg. 2017. Shoreline hardening affects nekton biomass, size structure, and taxonomic diversity in nearshore waters, with responses mediated by functional species groups. Estuaries and Coasts: 1-21. doi: 10.1007/s12237-017-0214-5.

Koroleff, F. 1983. Determination of ammonia. In Methods of seawater analysis: second, revised and extended edition, eds. K Grasshoff, $\mathrm{M}$ Ehrhardt, and K Kremling. Weinheim.

Kuznetsova, Alexandra, Per Bruun Brockhoff, and Rune Haubo Bojesen Christensen. 2015. lmerTest: tests in linear mixed effects models. $R$ package version 2.0-29: 1-1.

Landschoff, Jannes, Dagmar Lackschewitz, Katharina Kesy, and Karsten Reise. 2013. Globalization pressure and habitat change: Pacific rocky shore crabs invade armored shorelines in the Atlantic Wadden Sea. Aquatic Invasions 8: 77-87. doi:10.3391/ai.2013.8.1.09. 
Li, Shanze, and Steven C. Pennings. 2016. Disturbance in Georgia salt marshes: variation across space and time. Ecosphere 7: e01487e01411. doi:10.1002/ecs2.1487.

Li, Shanze, and Steven C. Pennings. 2017. Timing of disturbance affects biomass and flowering of a saltmarsh plant and attack by stemboring herbivores. Ecosphere 8: e01675-e01679. doi:10.1002/ ecs2.1675.

Long, W. Christopher, Jacob N. Grow, John E. Majoris, and Anson H. Hines. 2011. Effects of anthropogenic shoreline hardening and invasion by Phragmites australis on habitat quality for juvenile blue crabs (Callinectes sapidus). Journal of Experimental Marine Biology and Ecology 409: 215-222. doi:10.1016/j.jembe.2011.08. 024.

Lowe, Michael R., and Mark Peterson. 2014. Effects of coastal urbanization on salt-marsh faunal assemblages in the northern Gulf of Mexico. Marine and Coastal Fisheries 6: 89-107.

Lowe, Michael R., and Mark S. Peterson. 2015. Body condition and foraging patterns of nekton from salt marsh habitats arrayed along a gradient of urbanization. Estuaries and Coasts 38: 800-812. doi: 10.1007/s12237-014-9865-7.

McClelland, James W., Ivan Valiela, and Robert H. Michener. 1997. Nitrogen-stable isotope signatures in estuarine food webs: a record of increasing urbanization in coastal watersheds. Limnology and Oceanography 42: 930-937. doi:10.4319/lo.1997.42.5.0930.

Mouton, Edmond C., and Darryl L. Felder. 1995. Reproduction of the fiddler crabs Uca longisignalis and Uca spinicarpa in a Gulf of Mexico salt marsh. Estuaries and Coasts 18: 469-481.

Nordstrom, Karl F., and Nancy L. Jackson. 2013. Removing shore protection structures to facilitate migration of landforms and habitats on the bayside of a barrier spit. Geomorphology 199: 179-191. doi:10. 1016/j.geomorph.2012.11.011.

Nordstrom, K.F., N.L. Jackson, P. Rafferty, N.A. Raineault, and R. Grafals-Soto. 2009. Effects of bulkheads on estuarine shores: an example from Fire Island National Seashore, USA. J Coast Res I: 188-192.

Oksanen, Jari, F Guillaume Blanchet, Roeland Kindt, Pierre Legendre, Peter R Minchin, R B OHara, Gavin L Simpson, et al. Vegan: community ecology package. $R$ package version $2.0-29$.

Pethick, John. 2001. Coastal management and sea-level rise. Catena 42: 307-322.

Popkin, Gabriel. 2015. Breaking the waves. Science. doi: 10.1126/ science.350.6262.756.
R Core Team (2015). R: A language and environment for statistical computing. R Foundation for Statistical Computing, Vienna, Austria. URL https://www.R-project.org/.

Rice, E.W., R.B. Baird, A.D. Eaton, and L.S. Clesceri. 2012. Standard methods for the examination of water and wastewater. 22nd ed. New York: American Public Health Association.

Scyphers, Steven B., J. Steven Picou, and Sean P. Powers. 2014. Participatory conservation of coastal habitats: the importance of understanding homeowner decision making to mitigate cascading shoreline degradation. Conservation Letters 8: 41-49. doi:10.1111/ conl.12114.

Siddon, E.C., Janet T. Duffy-Anderson, and F.J. Mueter. 2011. Community-level response of fish larvae to environmental variability in the southeastern Bering Sea. Marine Ecological Progress Series 426: 225-239. doi:10.3354/meps09009.

Silliman, Brian R., and Mark D. Bertness. 2004. Shoreline development drives invasion of Phragmites australis and the loss of plant diversity on New England salt marshes. Conservation Biology 18: 14241434.

Sobocinski, Kathryn L., Jeffery R. Cordell, and Charles A. Simenstad. 2010. Effects of shoreline modifications on supratidal macroinvertebrate fauna on Puget Sound, Washington beaches. Estuaries and Coasts 33: 699-711. doi:10.1007/s12237-009-9262-9.

Stewart-Oaten, Allan, William W. Murdoch, and Keith R. Parker. 1986. Environmental impact assessment: pseudoreplication in time? Ecology 67. Ecological Society of America: 929-940.

Valiela, Ivan, and Carol S. Rietsma. 1995. Disturbance of salt marsh vegetation by wrack mats in Great Sippewissett Marsh. Oecologia 102. Springer-Verlag: 106-112. doi:10.1007/BF00333317.

Wahl, M.H., H.N. McKellar, and T.M. Williams. 1997. Patterns of nutrient loading in forested and urbanized coastal streams. Journal of Experimental Marine Biology and Ecology 213: 111-131.

Walters, Keith, John J. Hutchens, Eric T. Koepfler, and James O. Luken. 2010. Local-scale characteristics of high marsh communities next to developed and undeveloped shorelines in an ocean-dominated estuary, Murrells Inlet, SC. Aquatic Sciences 72: 309-324. doi:10.1007/ s00027-010-0137-8.

Zimmer, M., S. C. Pennings, T. Buck, and T. Carefoot. 2002. Speciesspecific patterns of litter processing by terrestrial isopods (Isopoda: Oniscidea) in high intertidal salt marshes and coastal forests. Functional Ecology 16:596-607. 